\title{
Invited authors \\ The role of exercise for fall prevention in older age
}

\author{
Anne Tiedemann \\ Catherine Sherrington \\ University of Sydney, Australia \\ Stephen R. Lord \\ University of New South Wales, Australia
}

\begin{abstract}
Falls are a common, costly and preventable consequence of sensorimotor impairments that increase in prevalence with advancing age. A fall occurs when the physical ability of the individual is unable to match the immediate demands of the environment and/or of the activity being undertaken. Targeted exercise aimed at improving the physical ability of the individual, such as balance and strength training, is crucial for promoting functional independence and mobility and reducing the risk of falling in older age. Exercise programs that provide a high challenge to balance, have a high dose, include progression of intensity over time and are ongoing are most effective for preventing falls. This paper provides guidance to health professionals involved with the prescription of physical activity and exercise to older people regarding the safe and effective provision of programs aimed at improving strength and balance and preventing falls in older age.
\end{abstract}

Keywords: accidental falls, aged, exercise, postural balance

Resumo- - "O papel do exercício na prevenção de quedas entre idosos." As quedas são uma consequência comum, caras e evitáveis decorrentes das deficiências sensoriomotoras que aumentam em incidência com o avanço da idade. A queda ocorre quando a capacidade física do indivíduo não responde às demandas imediatas do ambiente e/ou da atividade realizada. Exercícios específicos destinados a melhorar a capacidade física do indivíduo, tais como equilíbrio e treinamento de força, são fundamentais para promover a independência funcional e mobilidade, e reduzir o risco de cair em idade mais avançada. Programas de exercício que oferecem um desafio maior ao equilíbrio, oferecidos com frequência, que incluem a progressão da intensidade ao longo do tempo e sem interrupção são mais eficazes para a prevenção de quedas. Este documento fornece orientações para os profissionais de saúde envolvidos com a prescrição de atividade física e exercício físico para pessoas idosas em relação à prestação segura e eficaz de programas destinados a melhorar a força e equilíbrio e prevenção de quedas na velhice.

Palavras-chaves: quedas acidentais, exercício, idade, equilíbrio postural

Resumen-“El papel del ejercicio para la prevención de caídas en la vejez." Las caídas son una consecuencia común, costosa y prevenibles de discapacidades sensoriomotoras resultantes de ese aumento de la incidencia con la edad. La caída se produce cuando la capacidad física del individuo no responde a las exigencias inmediatas del medio ambiente y/o de la actividad desarrollada. Los ejercicios específicos diseñados para mejorar la capacidad física del individuo, tales como el equilibrio y entrenamiento de la fuerza, es crucial para promover la independencia funcional y la movilidad, y reducir el riesgo de caer en la vejez. Los programas de ejercicios que ofrecen un mayor desafío al equilibrio, se ofrece con frecuencia, incluyendo la progresión de la intensidad con el tiempo y sin interrupción son los más efectivos para la prevención de caídas. Este documento proporciona una guía para los profesionales de la salud implicados en la prescripción de la actividad física y el ejercicio para las personas ancianas con respecto a la prestación segura y eficaz de los programas destinados a mejorar la fuerza y el equilibrio y la prevención de caídas en la vejez.

Palabras claves: las caídas accidentales, el ejercicio, vejez, equilibrio postural

\section{Background}

Falls are a major cause of dependence in older age and can result in long term disability, loss of mobility, reduced quality of life and even death (Campbell et al., 1990). Falling in older age greatly increases the risk of being admitted to a residential aged care facility (Tinetti \& Williams,1997) and falls account for approximately $18 \%$ of emergency hospital admissions by older people (Bell, Talbot-Stern, \& Hennessy, 2000).

At least one in three community-dwelling people aged 65 years and over will fall each year, a figure that will grow in 
significance with the ageing of the world's population, particularly in Brazil where the number of people aged over 80 years is predicted to increase substantially by 2050 (Perls, 2009). Falls in frailer older people such as residents of aged care facilities and hospital inpatients are even more common (Cameron et al., 2010). Studies undertaken in Sweden (Sjogren \& Bjornstig, 1989), the United States (Alexander, Rivara, \& Wolf, 1992; Carroll, Slattum, \& Cox, 2005) and the United Kingdom (Scuffham, Chaplin, \& Legood, 2003) have drawn attention to the significant direct health care costs required for the treatment of fall-related injury. Furthermore, Australian data estimate the economic cost of fall related injury to be more than double the cost attributed to road trauma each year (Moller, 2000) and globally falls are the second leading cause of unintentional injury death, after road traffic injuries (World Health Organization, 2007). The high economic burden and substantial personal cost clearly demonstrate that falls are a public health issue that demand attention.

Physical activity is identified by the World Health Organization (World Health Organization, 2010) as a part of the solution to the challenge of population ageing and the associated need for global action to ensure health and wellbeing is maintained into later life. Furthermore, there is clear evidence that specific exercise programs that challenge balance are most effective in preventing falls (Sherrington, Tiedemann, Fairhall, Close \& Lord, 2011).

Falls, defined as "unexpected events in which the participant comes to rest on the ground, floor, or lower level" (Lamb, Jorstad-Stein, Hauer \& Becker, 2005) do not occur at random and can be predicted by assessing certain risk factors (Ganz, Bao, Shekelle \& Rubenstein, 2007; Tiedemann, Shimada, Sherrington, Murray \& Lord, 2008). Some of these risk factors (e.g., reduced muscle strength and impaired balance and gait) can be improved with exercise (Howe, Rochester, Neil, Skelton \& Ballinger, 2011), whereas others (e.g., poor vision, psychoactive medication use) require other intervention approaches.

An extensive body of fall prevention research published in the past 25 years provides a good understanding of the size of the problem, the factors that increase a person's risk of falling and the consequences of falls. There have also been many randomized controlled trials (RCTs) conducted to explore the effectiveness of a range of fall prevention strategies.

\section{Exercise is a key to fall prevention}

We have used the definitions of exercise and physical activity from the American College of Sports Medicine (ACSM) Position Stand on Exercise and Physical Activity for Older Adults in this al paper (Chodzko-Zajko et al., 2009). Physical activity is body movement that is produced by the contraction of skeletal muscles and that increases energy expenditure. Exercise is planned, structured, and repetitive movement to improve or maintain one or more components of physical fitness.
An age-related decline in function of the sensorimotor systems that contribute to the maintenance of postural control (Lord \& Ward, 1994), leads to an increased risk of falling with advanced age. Of particular importance is muscle strength and power in the lower limbs, reaction time and balance, all of which can be improved with appropriate exercise. (Liu, \& Latham, 2009; Lord, Ward, Williams \& Strudwick, 1995; Howe et al., 2011).

Clinical trials provide strong evidence that exercise as a single intervention can prevent falls in older community dwellers (Gillespie et al., 2012; Sherrington et al., 2008). Exercise is effective in reducing the risk of falling for both general community-dwellers (Woo, Hong, Lau \& Lynn, 2007) and people at a high risk of falls (Skelton, Dinan, Campbell $\&$ Rutherford, 2005). The recent Cochrane review of interventions to prevent falls in community dwelling older people concluded that exercise can reduce the risk and rate of falls in older people by between 15 and $32 \%$, depending on the type of program and measures used to assess effectiveness (Gillespie et al., 2012).

The role of physical activity (as opposed to structured exercise programs) in fall prevention is less clear. It is known that more active people have fewer falls (Heesch, Byles \& Brown, 2008) and that this relationship persists after adjustment for other variables which are associated with falls. However currently there is no evidence that simply providing advice about being more active is an effective fall prevention strategy.

\section{Other interventions to prevent falls}

Multifaceted interventions can also prevent falls (Gillespie et al., 2012) and many of these include exercise. Several other single interventions are also effective for preventing falls: home safety modifications in people who have previously fallen (Clemson, Mackenzie, Ballinger, Close, \& Cumming, 2008), reducing intake of psychoactive medications (Campbell, Robertson, Gardner, Norton, \& Buchner, 1999), enhanced podiatry (Spink et al., 2011), cataract surgery (Harwood et al., 2005), the use of single lens rather than bi-, tri- or multifocal glasses for outdoor mobility (Haran et al., 2010) and the insertion of cardiac pacemakers for the small proportion of people who experience blackouts and are diagnosed with the cardio-inhibitory form of carotid sinus hypersensitivity (Kenny et al., 2001).

Single and multiple fall prevention interventions appear to have a similar impact on falls, (Campbell \& Robertson, 2007) however exercise as a single intervention is a more cost-effective approach (Davis et al., 2010). Therefore, in the absence of contraindications, exercise should be considered a core fall prevention strategy for older people. People with risk factors not amenable to change with exercise should also be referred for appropriate care, such as medication review or cataract surgery for example. This article provides guidance on the prescription of exercise programs aimed at preventing falls in older people. 


\section{Exercise and physical activity guidelines for older people}

Physical activity has wide ranging benefits for health and well-being and can reduce the risk of disease onset and manage chronic conditions such as arthritis, diabetes, heart and respiratory conditions (Nelson et al.,2007). The ACSM and the American Heart Association (AHA) physical activity recommendation statement for older adults applies to all adults aged 65 years and over, and to adults aged 50-64 years with clinically significant chronic conditions or functional limitations that affect movement ability, fitness, or physical activity (Nelson et al., 2007). The recommendations state that older adults should: 1. Do moderately intense aerobic exercise, for 30 minutes per day, 5 days a week, or do vigorously intense aerobic exercise, for 20 minutes per day, 3 days a week, and 2. Do 8-10 strengthtraining exercises, 10-15 repetitions of each exercise, 2-3 times per week and 3. If at risk of falling, perform balance exercises and 4. Have a physical activity plan.

With regard to point 3 above, as there is evidence that appropriate exercise can prevent falls in the general population rather than only in high risk groups (Sherrington et al., 2008) we suggest that all older adults should be encouraged to undertake balance training.

The ACSM position stand on resistance training for healthy adults recommends modifications to the rate of progression, intensity and mode and frequency of resistance exercise for safe and effective prescription for older people (Ratamess et al., 2009). Despite the emphasis in the fall prevention literature on the importance of balance training for preventing falls (Sherrington et al., 2008), it is likely that strength training is also important since strength declines steadily after the age of 40 (Kallman, Plato, \& Tobin, 1990), and impaired lower limb muscle strength has been identified as an important fall risk factor (Moreland, Richardson, Goldsmith, \& Clase, 2004). Exercises that focus on building strength in the lower limb muscle groups (Barnett, Smith, Lord, Williams, \& Bauman, 2003; Robertson, Campbell, Gardner, \& Devlin, 2002; Clemson et al., 2012) and muscles of the ankles and feet (Spink et al., 2011) have been included in successful fall prevention programs.

\section{Fall prevention exercise prescription}

Exercise programs that include exercises that challenge balance are more effective in preventing falls than programs that do not challenge balance (Sherrington et al., 2011). Effective challenge to balance is provided with exercises that are conducted whilst standing in which participants aim to a) stand with their feet closer together or on one leg b) minimise use of their hands to assist balance and c) practice controlled movements of the body's centre of mass.

The initial prescription of difficulty of balancechallenging exercise should be guided by the capabilities of the individual and should consider safety. When a balance task is mastered in a stable manner without the need for upper limb support, the task should be progressed to increase the challenge to balance. Methods to increase the intensity and effectiveness of balance challenging exercises over time include a) using progressively difficult postures with a gradual reduction in the base of support (e.g. twolegged stand, semi-tandem stand, tandem stand, one-legged stand), b) using movements that perturb the centre of gravity (e.g. tandem walk, circle turns, leaning and reaching activities, stepping over obstacles), c) specific resistance training for postural muscle groups (e.g. heel stands, toe stands, hip abduction with added weights to increase intensity, unsupported sit to stand practice), and/ or d) reducing sensory input (e.g. standing with eyes closed, standing/ walking on an unstable surface such as foam mats) (ChodzkoZajko et al., 2009). Further challenge can be provided by the use of dual tasks, such as combining a memory task with a gait training exercise or a hand-eye co-ordination activity with a balance task.

Balance is a co-ordination task that involves anticipatory and ongoing postural adjustments to maintain the body's centre of mass within manageable limits of the base of support, as in standing or sitting, or in transit to a new base of support, as in walking (Winter, 1995). Activities such as aerobics, tennis, yoga and dancing have not been formally evaluated in the fall prevention context but as they require co-ordination practice, they are likely to be beneficial in maintaining balance abilities for middle aged people and more able older people. For older people with poorer postural control, these activities may increase risk of falling so individually prescribed exercises which safely challenge balance, such as those in the Otago exercise programme (Robertson et al., 2002), (for details, visit: http://www.acc. co.nz/otagoexerciseprogramme) may be more appropriate. The Otago programme involves five home visits over a six month period by a health professional to prescribe the exercise program and monitor compliance and progression. It also includes a walking program where appropriate for the individual. It has been shown to reduce the rate of falls by $35 \%$. Similarly, the Lifestyle integrated Functional Exercise (LiFE) balance and strength training program (Clemson et al., 2012) is a validated, partially supervised, home-based fall prevention exercise program that has been shown to reduce fall rates by $31 \%$. Furthermore, since the LiFE exercise program includes fall prevention exercises that are embedded into daily activity, it may represent an attractive mode of exercise that is easily adopted and maintained by older people.

In addition to the importance of exercise with a high challenge to balance, there are also bigger fall prevention effects with a higher dose of exercise (e.g. a dose of more than 50 hours of exercise, typically $2 \times 1$ hour sessions for six months). It is likely that exercise needs to be ongoing to have a lasting effect on fall rates. Therefore programs should offer ongoing exercise, or encourage people to undertake ongoing exercise at the end of a short-term formal program as recommended by the ACSM (Nelson et al., 2007).

A recent updated meta-analysis and meta-regression of 
54 randomised controlled trials by our group (Sherrington et al., 2011) indicates that the optimal exercise program for preventing falls is one that contains the following three elements: exercises that provide a high challenge to balance, exercise of a high dose, and no walking program. This combination of factors resulted in a significant $38 \%$ reduction in the rate of falls (adjusted pooled rate ratio $=$ $0.62,95 \%$ confidence interval 0.54 to 0.73 ). In comparison, programs that included a high challenge to balance and a high dose but also included a walking program resulted in a lower $21 \%$ reduction in the rate of falls (adjusted pooled rate ratio $=0.79,95 \%$ confidence interval 0.70 to 0.89 ).

The apparently lesser effect on fall rates of the inclusion of walking programs may be due to: a) increased exposure to hazards that contribute to fall risk with walking, b) walking taking time away from high level balance training or c) confounding of the results as walking programs were more likely to be prescribed in high risk populations (e.g. in residential care) and the beneficial effects of exercise in this population are less marked. Although walking appears not to be an effective fall prevention strategy in some studies there are other benefits of walking programs for older people (Nelson et al., 2007; Murphy, Nevil, Murtagh, \& Holder, 2007). We suggest walking training be included in a fall prevention program as long as it is not at the expense of balance training. However, high risk individuals should not be prescribed brisk walking programs due to the increased risk of falls with this activity (Ebrahim, Thompson, Baskaran, \& Evans, 1997). The Otago Exercise Programme can be effective in preventing falls and includes the prescription of a walking program if the exercise provider considers the individual participant to be safely able to undertake such a program. We suggest that this approach be used for participants in fall prevention exercise programs.

In summary, a range of exercise programs which target balance and provide ongoing exercise are effective in preventing falls. These include: the Otago Programme of home-based balance and strength training (Robertson et al., 2002), the LiFE program of embedded balance and strength training into habitual daily routines (Clemson et al., 2012), group based-Tai Chi (Li et al., 2005; Voukelatos, Cumming, Lord, \& Rissel, 2007) and other group-based balance and strengthening exercise (Lord, et al., 2003; Barnett et al., 2003). As exercises that focused on muscles of the ankles and feet were considered to be important components of a successful podiatry fall prevention trial (Spink et al., 2011) such exercises could also be considered for inclusion in general exercise programs, and especially for the high proportion of older people with foot problems. Program design should meet the needs and abilities of the target population to ensure it provides exercise that is challenging yet safe.

\section{Special consideration of clinical groups}

The ACSM states that "virtually all sedentary individuals can begin a moderate exercise program safely." The ACSM pre-exercise screening and medical clearance recommen- dations for older adults are: 1) if an older person wanting to begin moderate exercise is apparently healthy, medical screening is not necessary, and 2) if an older person wanting to begin vigorous exercise is apparently healthy, medical screening is recommended. Additionally, people with known cardiac, pulmonary, or metabolic diseases or other factors which increase the risk of adverse effects should also undergo medical screening before beginning an exercise program. Cessation of exercise and medical review is recommended if a person experiences chest pain, shortness of breath or dizziness during physical activity (Gill, DiPietro, $\&$ Krumholz, 2000). Finally, exercise intensity should be progressed in a tailored manner that takes into account individual tolerances and preferences (Chodzko-Zajko et al., 2009).

People aged 85 years and over and those with chronic disease, such as Parkinson's disease and previous stroke or functional limitations, are at a substantially increased risk of falls. While there is evidence that well-designed exercise programs can prevent falls in high risk populations (Skelton et al., 2005; Barnett et al., 2003), attention to safety and supervision is crucial to ensure that exercise programs do not cause the falls they are attempting to prevent. Further research is needed to determine the optimal approach for preventing falls in people with specific medical conditions such as Parkinson's disease (Goodwin, Richards, Taylor, Taylor, \& Campbell, 2008) and stroke (Batchelor, Hill, Mackintosh, \& Said, 2010) as there is limited evidence of effective exercise programs targeting these clinical groups. Similarly, trials of exercise in the cognitively impaired population have not had falls outcomes, but people with a mild cognitive impairment would be expected to benefit from carefully prescribed and monitored exercise programs where safety is thoroughly considered.

For people with certain medical conditions, special precautions may be required to ensure safe and effective exercise participation. For example, people with osteoarthritis may require analgesia (American Geriatrics Society Panel on Exercise and Osteoarthritis, 2001) people with asthma (National Asthma Council of Australia, 2006) and heart disease/ angina (Briffa et al., 2006) may require the use of medication and people with diabetes may require additional carbohydrate prior to or during exercise (Sigal, Kenny, Wasserman, Castaneda-Sceppa, \& White, 2006). Additionally, exercise guidelines recommend an extended cool down period after physical activity for older people to reduce the chance of hypotension, syncope (fainting) or arrhythmias during the post-exercise recovery period. Dehydration is also more likely to occur in older people taking diuretics, so fluid intake is recommended before, during and after exercise (Fletcher et al., 2001).

\section{Promoting exercise adherence}

Low rates of physical activity and exercise participation globally provide a major hurdle to achieving large public health gains as a result of active lifestyles. Worldwide around 
$31 \%$ of adults are not participating in the recommended minimum level of physical activity per week and this proportion rises to at least $40 \%$ in people aged 60 years and over in most regions of the world (Hallal et al., 2012). In addition to low rates of uptake, maintaining participation in physical activity is a challenge, since around half of people who start a program dropout within six to 12 months (Dishman, 1982), and those who dropout are likely to be most in need of regular exercise (Dishman, Sallis, \& Orenstein, 1985). Clearly better implementation and support strategies are needed to boost participation and long term commitment to active lifestyles.

Extensive research has identified factors that influence uptake and attitudes to fall prevention exercise programs among older people (Yardley et al., 2007; Yardley, DonovanHall, Francis, \& Todd, 2006). This research shows that programs with a positive health message and goal are more likely to result in higher levels of acceptance from older people than programs aimed at solely "preventing falls" due to the stigma that surrounds ageing and falling for older people (Bunn, Dickinson, Barnett-Page, McInnes, \& Horton, 2008). Furthermore, other research has identified participant and program-level facilitators and barriers to participation in falls prevention exercise interventions by older people (Bunn et al., 2008). High exercise self-efficacy, past exercise participation, good general health and functional independence were participant-specific facilitators. The program characteristics that were associated with improved program adherence were frequent, moderate duration activity, program accessibility and convenience, emphasis on social aspects, strong leadership and individually tailored exercise. These factors should be considered when designing exercise programs for older people in order to maximise uptake and participation and ultimately to maximise the benefits of such programs.

\section{Further research}

Despite the strong evidence supporting some exercise modalities for preventing falls, there is uncertainty about the effects of other organised activities such as dance, yoga, lawn bowls and golf, and walking and strength training as single fall prevention interventions. Also, direct comparisons of different exercise interventions have not been sufficiently evaluated in the research context. It has not been demonstrated prospectively whether mid-life exercise can prevent falls in older age or whether exercise can prevent fall-related fractures in an appropriately designed and powered randomized controlled trial. There have also been few largescale trials of exercise in residential care and hospital settings. The relative benefit of exercise as a single intervention versus multiple interventions also requires further investigation.

\section{Summary}

Falls can have a huge impact on older people and present a major burden to health care providers, health systems and to the wider community. Encouragingly though, there is now extensive evidence about effective exercise that plays a key role in maintaining balance and mobility and preventing falls in older age. More active people experience fewer falls but it does not appear that we can prevent falls by simply encouraging older people to be more active. Undertaking specific balance challenging exercise on a regular basis for a sustained period of time is essential to significantly reduce fall risk. This targeted approach is the key to reducing fallrelated injury and the associated public health burden.

\section{References}

Alexander, B.H., Rivara, F.P., \& Wolf, M.E. (1992). The cost and frequency of hospitalization for fall-related injuries in older adults. American Journal of Public Health, 82(7), 1020-3.

American Geriatrics Society Panel on Exercise and Osteoarthritis. (2001). Exercise Prescription for Older Adults with Osteoarthritis Pain: Consensus Practice Recommendations - A supplement to the AGS Clinical Practice Guidelines on the management of chronic pain in older adults. Journal of the American Geriatrics Society, 49, 808-23.

Barnett, A., Smith, B., Lord, S.R., Williams, M., \& Bauman, A. (2003). Community-based group exercise improves balance and reduces falls in at-risk older people: a randomised controlled trial. Age and Ageing, 32 (4), 407-14.

Batchelor, F., Hill, K., Mackintosh, S., \& Said, C. (2010). What Works in Falls Prevention After Stroke?: A Systematic Review and Meta-Analysis. Stroke, 41, 1715-22.

Bell, A., Talbot-Stern, J., \& Hennessy, A. (2000). Characteristics and outcomes of older patients presenting to the emergency department after a fall: a restrospective analysis. Medical Journal of Australia, 173 (4), 179-82.

Bunn, F., Dickinson, A., Barnett-Page, E., McInnes, E., \& Horton, K. (2008). A systematic review of older people's perceptions of facilitators and barriers to participation in falls-prevention interventions. Ageing and Society, 28 (4), 449-72.

Briffa, T., Allan, R., Maiorana, A., Oldenburg, B., Sammel, N., Stubbs, A., \& Sheerin, N. (2006). On behalf of the Executive Working Group and National Forum Participants. National Heart Foundation of Australia physical activity recommendations for people with cardiovascular disease. National Heart Foundation of Australia. Sydney, Australia.

Cameron, I.D., Murray, G.R., Gillespie, L.D., Robertson, M.C., Hill, K.D., Cumming, R.G., \& Kerse, N. (2010). Interventions for preventing falls in older people in nursing care facilities and hospitals. Cochrane Database of Systematic Reviews, (1), CD005465. doi: 10.1002/14651858.CD005465.pub2.

Campbell, A.J., Borrie M.J., Spears, G.F., Jackson, S.L., Brown, J.S., \& Fitzgerald, J.L.(1990). Circumstances and consequences of falls experienced by a community population 70 years and over during a prospective study. Age and Ageing, 19 (2), 13641.

Campbell, A.J., \& Robertson, M.C. (2007). Rethinking individual and community fall prevention strategies: a meta-regression comparing single and multifactorial interventions. Age and Ageing, 36 (6), 656-62. doi: 10.1093 /ageing/afm122.

Campbell, A.J., Robertson, M.C., Gardner, M.M., Norton, R.N., \& Buchner, D.M. (1999). Psychotropic medication withdrawal and a home based exercise programme to prevent falls: results of a randomised controlled trial. Journal of the American Geriatrics Society, 47, 850-3. 
Carroll, N., Slattum, P., \& Cox, F. (2005). The cost of falls among the community-dwelling elderly. Journal of Managed Care Pharmacy, 11 (4), 307-16.

Chodzko-Zajko, W.J, Proctor, D.N., Fiatarone Singh, M.A., Minson, C.T., Nigg, C.R., Salem, G.J., \& Skinner, J.S. (2009). American College of Sports Medicine Position stand on Exercise and Physical Activity for Older Adults. Medicine \& Science in Sports \& Exercise, 41, 1510-30.

Clemson, L., Mackenzie, L., Ballinger, C., Close, J.C.T., \& Cumming, R.G. (2008). Environmental Interventions to Prevent Falls in Community-Dwelling Older People: A Meta-Analysis of Randomized Trials. Journal of Aging and Health, 20 (8), 954-71.

Clemson, L., Singh, M.A.F., Bundy, A., Cumming, R.G., Manollaras, K., O’Loughlin, P., \& Black, D. (2012). Integration of balance and strength training into daily life activity to reduce rate of falls in older people (the LiFE study): randomised parallel trial. British Medical Journal, 345. doi: 10.1136/ bmj.e4547.

Dishman, R.K. (1982). Compliance/adherence in health-related exercise. Health Psychology, 1 (3), 237-67.

Davis, J.C., Robertson, M.C., Ashe, M.C, Liu-Ambrose, T., Khan, K.M., \& Marra, C.A. (2010). Does a home-based strength and balance programme in people aged ?80 years provide the best value for money to prevent falls? A systematic review of economic evaluations of falls prevention interventions. British Journal of Sports Medicine, 44 (2), 80-9.

Dishman, R.K., Sallis, J.F., \& Orenstein, D.R. (1985). The determinants of physical activity and exercise. Public Health Reports, 100(2), 158-71.

Ebrahim, S., Thompson, P.W., Baskaran, V., \& Evans, K. (1997). Randomized placebo-controlled trial of brisk walking in the prevention of postmenopausal osteoporosis. Age and Ageing, 26 (4), 253-60.

Fletcher, G.F., Balady, G.J., Amsterdam, E.A., Chaitman, B., Eckel, R., Fleg, J., ... \& Bazzarre, T. (2001). Exercise standards for testing and training: a statement for healthcare professionals from the American Heart Association. Circulation, 104, 1694740 .

Ganz, D.A., Bao, Y., Shekelle, P.G., \& Rubenstein, L.Z. (2007). Will my patient fall? Journal of the American Medical Association, 3 (297), 77-86.

Gillespie, L.D., Robertson, M.C., Gillespie, W.J., Sherrington, C., Gates, S., Clemson, L.M., \& Lamb, S.E. (2012). Interventions for preventing falls in older people living in the community. Cochrane Database of Systematic Reviews, (9),CD007146, doi:10.1002/14651858.CD00 7146.pub3.

Gill, T.M., DiPietro, L., \& Krumholz, H.M. (2000). Role of Exercise Stress Testing and Safety Monitoring for Older Persons Starting an Exercise Program. Journal of the American Medical Association, 284, 342-9.

Goodwin, V.A., Richards, S.H., Taylor, R.S., Taylor, A.H., \& Campbell, J.L. (2008). The effectiveness of exercise interventions for people with Parkinson's disease: A systematic review and meta-analysis. Movement Disorders, 23, 631-40.

Hallal, P.C., Andersen, L.B., Bull, F.C., Guthold, R., Haskell, W., \& Ekelund, U. (2012). Global physical activity levels: surveillance progress, pitfalls, and prospects. The Lancet, 380 (9838), 247-57.

Haran, M.J., Cameron, I.D., Ivers, R.Q., Simpson, J.M., Lee, B.B., Tanzer, M., ... \& Lord, S.R. (2010). Effect on falls of providing single lens distance vision glasses to multifocal glasses wearers: VISIBLE randomised controlled trial. British Medical Journal, 340. doi:10.1136/bmj.c2265.
Harwood, R.H., Foss, A.J., Osborn, F., Gregson, R.M., Zaman, A., \& Masud, T. (2005). Falls and health status in elderly women following first eye cataract surgery: a randomised controlled trial. British Journal of Ophthalmology, 89 (1), 53-9.

Heesch, K.C., Byles, J.E., \& Brown, W.J. (2008). Prospective association between physical activity and falls in communitydwelling older women. Epidemiology and Community Health, 62, 421-6.

Howe, T.E, Rochester, L., Neil, F., Skelton, D.A., Ballinger, C. (2011). Exercise for improving balance in older people. Cochrane Database of Systematic Reviews, 9 (11), CD004963, doi: 10.1002/14651858.CD004963.pub3.

Kallman, D.A., Plato, C.C., \& Tobin, J.D. (1990). The role of muscle loss in the age-related decline of grip strength: crosssectional and longitudinal perspectives. Journal of Gerontology, 45 (3), M82-8.

Kenny, R.A.M., Richardson, D.A., Steen, N., Bexton, R.S., Shaw, F.E., \& Bond, J. (2001). Carotid sinus syndrome: a modifiable risk factor for nonaccidental falls in older adults (SAFE PACE). Journal of the American College of Cardiology, 38 (5), 14916.

Lamb, S.E., Jorstad-Stein, E.C., Hauer, K., \& Becker, C. (2005). Prevention of Falls Network Europe and Outcomes Consensus Group Development of a common outcome data set for fall injury prevention trials: the Prevention of Falls Network Europe consensus. Journal of the American Geriatrics Society, 53, 1618-22.

Li ,F., Harmer, P., Fisher, K.J., McAuley, E., Chaumeton, N., Eckstrom, E., \& Wilson, N.L. (2005). Tai Chi and fall reductions in older adults: a randomized controlled trial. Journals of Gerontology Series A-Biological Sciences \& Medical Sciences, 60, 187-94.

Liu, C.J., \& Latham, N. (2009). Progressive resistance strength training for improving physical function in older adults. Cochrane Database of Systematic Reviews, (3), CD00275 9, doi: 10.1002/14651858.CD002759.pub2.

Lord, S.R., Castell, S., Corcoran, J., Dayhew, J., Matters, B., Shan, A., \& Williams, P. (2003). The effect of group exercise on physical functioning and falls in frail older people living in retirement villages: a randomized, controlled trial. Journal of the American Geriatrics Society, 51 (12), 1685-92.

Lord, S.R., \& Ward, J.A. (1994). Age-associated differences in sensori-motor function and balance in community dwelling women. Age and Ageing, 23 (6), 452-60.

Lord, S.R., Ward, J.A., Williams, P., \& Strudwick, M. (1995). The effect of a 12-month exercise trial on balance, strength, and falls in older women: a randomized controlled trial. Journal of the American Geriatrics Society, 43 (11), 1198-206.

Moller, J. (2000). Changing resource demands related to fall injury in an ageing population. NSW Public Health Bulletin, 13 (1-2), 3-6.

Moreland, J.D., Richardson, J.A., Goldsmith, C.H., \& Clase, C.M. (2004). Muscle weakness and falls in older adults: A systematic review and meta-analysis. Journal of the American Geriatrics Society, 52, 1121-9.

Murphy, M.H., Nevil,1 A.M., Murtagh, E.M., \& Holder, R.L. (2007). The effect of walking on fitness, fatness and resting blood pressure: a meta-analysis of randomised, controlled trials. Preventive Medicine, 44, 377-85.

National Asthma Council of Australia. (2006). Asthma management handbook. Melbourne.

Nelson, M.E., Rejeski, W.J., Blair, S.N., Duncan, P.W., Judge, J.O., King, A.C., ... \& Castaneda-Sceppa, C. (2007). Physical activity and public health in older adults: recommendation from 
the American College of Sports Medicine and the American Heart Association. Medicine \& Science in Sports \& Exercise, 39, 1435-45.

Perls, T. Health and disease in people over 85. (2009). Despite disease, disability is low. British Medical Journal, 339, b417.

Ratamess, N. A., Alvar, B. A., Evetoch, T. K., Housh, T. J., Kibler, W. B., Kraemer, W. J., \& Triplett, N. T. (2009). American College of Sports Medicine position stand on Progression Models in Resistance Training for Healthy Adults. Medicine \& Science in Sports \& Exercise, 41 (3), 687-708.

Robertson, M.C., Campbell, A.J., Gardner, M.M., \& Devlin, N. (2002). Preventing injuries in older people by preventing falls: a meta-analysis of individual-level data. Journal of the American Geriatrics Society, 50, 905-11.

Sigal, R.J., Kenny, G.P., Wasserman, D.H., Castaneda-Sceppa, C., \& White, R.D. (2006). Physical activity/exercise and type 2 diabetes: a consensus statement from the Ame-rican Diabetes Association. Diabetes Care, 29, 1433-8.

Scuffham, P., Chaplin, S., \& Legood, R. (2003). Incidence and cost of unintentional falls in older people in the United Kingdom. Journal of Epidemiology and Community Health, 57, 740-4.

Sherrington, C., Tiedemann, A., Fairhall, N., Close, J.C.T., \& Lord, S.R. (2011). Exercise to prevent falls in older adults: an updated meta-analysis and best practice recommen-dations. NSW Public Health Bulletin, 22, 78-83.

Sherrington, C., Whitney, J.C., Lord, S.R., Herbert, R.D., Cumming, R.G., \& Close, J.C.T. (2008). Effective Exercise for the Prevention of Falls: A Systematic Review and MetaAnalysis. Journal of the American Geriatrics Society, 56, 223443.

Sjogren, H., \& Bjornstig, U. (1989). Unintentional injuries among elderly people: incidence, causes, severity, and costs. Accident Analysis \& Prevention, 21 (3), 233-42.

Skelton, D., Dinan, S., Campbell, M., \& Rutherford, O. (2005). Tailored group exercise (Falls Management Exercise -- FaME) reduces falls in community-dwelling older frequent fallers (an RCT). Age and Ageing, 34 (6), 636-9.

Spink, M.J., Menz, H.B., Fotoohabadi, M.R., Wee, E., Landorf, K.B., Hill, K.D., \& Lord, S.R. (2011). Effectiveness of a multifaceted podiatry intervention to prevent falls in community dwelling older people with disabling foot pain: randomised controlled trial. British Medical Journal, 343 (7813), 31. doi:10.1136/bmj.d3411.

Tiedemann, A., Shimada, H., Sherrington, C., Murray, S., \& Lord, S. (2008). The comparative ability of eight functional mobility tests for predicting falls in community-dwelling older people. Age and Ageing, 37, 1-6.

Tinetti, M.E., \& Williams, C.S. (1997). Falls, injuries due to falls, and the risk of admission to a nursing home. New England Journal of Medicine, 337 (18), 1279-84.

Voukelatos, A., Cumming, R.G., Lord, S.R., \& Rissel, C. (2007). A randomized, controlled trial of tai chi for the prevention of falls: the Central Sydney tai chi trial. Journal of the American Geriatrics Society, 55, 1185-91.

Winter, D.A. (1995). A.B.C. Anatomy, biomechanics and control of balance during standing and walking. Ontario: Waterloo Biomechanics.

Woo, J., Hong, A., Lau, E., \& Lynn, H. (2007). A randomised controlled trial of Tai Chi and resistance exercise on bone health, muscle strength and balance in community-living elderly people. Age and Ageing, 36 (3), 262-8.

World Health Organization. (2007). WHO global report on falls prevention in older age. Retrieved from: http://www.who.int/ ageing/publications/Falls_prevention7March.pdf
World Health Organization. (2010). Global recommendations on physical activity for health. Retrieved from: http:// whqlibdoc.who.int/publications/2010/978924159 9979_eng.pdf

Yardley, L., Beyer, N., Hauer, K., McKee, K., Ballinger, C., \& Todd, C. (2007). Recommendations for promoting the engagement of older people in activities to prevent falls. Quality and Safety in Health Care, 16, 230-4.

Yardley, L., Donovan-Hall, M., Francis, K., \& Todd, C. (2006). Older people's views of advice about falls prevention: a qualitative study. Health Education Research, 21, 508-1.

\section{Authors' note}

Anne Tiedemann $\mathrm{PhD}$ and Catherine Sherrington $\mathrm{PhD}$ are associated with the Musculoskeletal Division, The George Institute for Global Health, University of Sydney, Australia

Stephen R Lord DSc is affiliated with the Falls and Balance Research Group, Neuroscience Research Australia, University of New South Wales, Randwick, Australia

\section{Correspondence}

Dr Anne Tiedemann

The George Institute for Global Health, PO Box M201

Missenden Rd NSW 2050 Australia

$\mathrm{T}+61296570393$

$\mathrm{F}+61296570301$

E-mail: atiedemann@georgeinstitute.org.au

\section{Acknowledgments}

Dr Tiedemann is funded by a National Health and Medical Research Council Australian Research Training Fellowship. Professor Lord and Dr Sherrington are supported by Australian National Health and Medical Research Council Fellowships. The funders had no role in study design or execution or in manuscript preparation.

This study was presented as part of an invited lecture at the $8^{\text {th }}$ International Congress of Physical Education and Human Movement and $14^{\text {th }}$ Symposium Paulista Physical Education.

Declaration of Conflicting Interests: The authors declared no conflicts of interest with respect to the research, authorship, and/ or publication of this article.

Manuscript received on March 30, 2013

Manuscript accepted on May 10, 2013 